\title{
Feto-maternal outcome in patients with couvelaire uterus: a 3 year study in a tertiary care hospital in rural Karnataka, India
}

\author{
Sunanda N., Sruthi T.*, Sheela S. R.
}

Department of Obstetrics and Gynecology, Sri Devaraj Urs Medical College, Kolar, Karnataka, India

Received: 16 November 2017

Accepted: 18 December 2017

\section{*Correspondence:}

Dr. Sruthi T.,

E-mail: sruthitalasila99@gmail.com

Copyright: (C) the author(s), publisher and licensee Medip Academy. This is an open-access article distributed under the terms of the Creative Commons Attribution Non-Commercial License, which permits unrestricted non-commercial use, distribution, and reproduction in any medium, provided the original work is properly cited.

\begin{abstract}
Background: Couvelaire uterus also known as uteroplacental apoplexy is a life threatening condition where abruptio placenta causes bleeding that penetrates into the uterine myometrium. It can only be diagnosed on direct visualization. Therefore, its occurrence is perhaps under reported and underestimated in the literature. The objective of this study was to determine the risk factors for couvelaire uterus and feto-maternal outcomes associated with couvelaire uterus in comparison with patients who presented with abruption without couvelaire uterus in a tertiary care hospital in rural Karnataka.

Methods: All women who had abruptio placenta who were delivered by cesarean section were included in the study. Cases were women with couvelaire uterus and controls were women without couvelaire uterus observed intraoperatively during cesarean section.

Results: Patients without couvelaire uterus had significantly more vaginal bleeding (22.2\% vs $75 \%)$. However, patients with couvelaire uterus had a higher incidence of PPH (66.7\% vs $28.6 \%)$, need for blood transfusion $(5.9 \pm 3.2$ pints vs $1.6 \pm 1.8$ pints), DIC (22.2\% vs $14.3 \%)$, maternal mortality (5.6\% vs 0$)$ and adverse neonatal outcome.

Conclusions: We conclude that patients with couvelaire uterus had an increased risk of maternal complications such as postpartum hemorrhage and disseminated intravascular coagulation which resulted in increased need for blood transfusion, prolonged hospital stay and maternal morbidity and mortality. Present study further highlights that adverse neonatal outcomes such as low birth weight, low Apgar score and neonatal death were more frequently associated with couvelaire uterus. Thus, the presence of couvelaire uterus may be considered as a severe form of abruption and such patients should be anticipated for higher incidence and risk for maternal and neonatal morbidity.
\end{abstract}

Keywords: Abruptio placenta, Couvelaire uterus, Maternal and neonatal morbidity, Maternal complications

\section{INTRODUCTION}

Couvelaire uterus or utero-placental apoplexy is a rare complication of placental abruption. Couvelaire was the first to describe this as a pathological entity in 1912. It occurs due to extensive extravasation of blood into the uterine muscles in association with severe form of concealed abruption placentae. It can only be diagnosed on direct visualization. Therefore its occurrence is perhaps under reported and underestimated in the literature.
On gross examination the uterus appears patchy or diffusely stained in port wine color due to petechial hemorrhages underneath the uterine peritoneum and extravasation of blood into uterine muscle. There may be effusion of blood in the peritoneal cavity, broad ligament, beneath the tubal serosa and in the substance of the ovaries. The muscle bundles of the uterine wall are heavily infiltrated with extravasated blood and edema fluid resulting in an atonic uterus. The resulting lacerations in the decidual layer also allows a free communication from the intradecidual space of the 
hematoma into the maternal circulation of the placenta releasing thromboplastin, which may result in disseminated intravascular coagulopathy (DIC). ${ }^{1,2}$

Abruptio placenta is an important cause of maternal and perinatal mortality and morbidity globally especially in developing countries. It is an important cause of vaginal bleeding in the latter half of pregnancy and accounts for $20-25 \%$ of antepartum hemorrhages.

The key factor in the pathophysiology is hemorrhage at the deciduo-placental interface. Small episodes may escape clinical detection, but severe grades impact significantly on fetal and maternal morbidity and mortality with the most frequent complications being fetal death, severe maternal shock, disseminated intravascular coagulopathy, postpartum hemorrhage (PPH), hepatic dysfunction and renal failure. It is also associated with increased need for massive blood transfusions, additional operative procedures like step wise devascularization, peri-partum hysterectomy to control PPH, ultimately resulting in increased need for Intensive care unit (ICU) admission and higher rates of maternal death. ${ }^{3,4}$

Abruptio placenta has been associated with adverse fetal outcomes including low birth weight, preterm birth, intrauterine growth restriction, birth asphyxia, fetal distress, low Apgar score, transfer to neonatal ICU, stillbirth, congenital anomalies and perinatal death. Although neonatal outcomes have improved in developed countries due to advances in neonatal care, the problem of perinatal deaths of severely preterm babies in developing countries remains problematic. Surviving babies also carry an increased risk of neurological handicap, including cerebral palsy.,

Several risk factors have been associated with abruptio placenta including previous history of small-for gestational age delivery, young or advanced maternal age ( $<20$ years or $\geq 35$ years), previous history of abruptio placenta, previous history of caesarean section, current diabetes mellitus, multiparity (especially grand multiparity), maternal cigarette smoking, multiple gestations, chronic hypertension, preeclampsia, premature rupture of membranes, thrombophilias, abdominal trauma and polyhydramnios..$^{5}$

Even though many studies have been reported on abruptio placenta and its adverse effects, there are no studies done on couvelaire uterus as a pathological entity and its correlation with the feto-maternal outcome.

The objective of this study was to determine the frequency, risk factors for couvelaire uterus and fetomaternal outcomes associated with couvelaire uterus in comparison with patients who presented with abruption without couvelaire uterus in a tertiary care hospital in rural Karnataka, India.

\section{METHODS}

It was a retrospective observational study

All women who had abruptio placenta who were delivered by cesarean section were included in the study.

Cases were women with couvelaire uterus and controls were women without couvelaire uterus observed intraoperatively.

Women who had abruptio placenta who delivered vaginally were excluded from the study.

The materials for this study were obtained by reviewing the records in the labor ward delivery register, the obstetric theatre, case notes from the medical records department and records of the new-born special care unit of the teaching hospital over the 3 year period, January 2014 to December 2016. Their clinical presentation and the overall maternal and perinatal outcomes including morbidity and mortality were looked into.

\section{RESULTS}

Postpartum hemorrhage was defined as loss of blood estimated to be more than $500 \mathrm{ml}$ from the genital tract, within $24 \mathrm{~h}$ of delivery.

Acute renal failure was defined as an abrupt loss of kidney function resulting in the retention of urea and other nitrogenous waste products and in the dysregulation of extracellular volume and electrolytes.

Preterm birth was defined as a birth occurring at less than 37 completed weeks of gestation.

Perinatal death was defined as fetal death that occurred in utero after gestational age of 28 weeks or more (stillbirth) or infant death that occurred at less than 7 days of age post-delivery (early neonatal death).

Low birth weight infant was defined as an infant having birth weight less than $2500 \mathrm{~g}$.

Fetal distress was defined as a compromised condition of the fetus, discovered during labor or intra partum period characterized by a markedly abnormal heart rate or rhythm.

Apgar score was defined as a measure of the physical condition of a newborn infant. It is obtained by adding points $(2,1$, or 0$)$ for heart rate, respiratory effort, muscle tone, response to stimulation, and skin coloration; a score of ten represents the best possible condition.

During the 3-year review period there were 18 cases of couvelaire uterus (group A) and 28 cases with abruption without couvelaire uterus (group B). 
There was no significant difference in the demographic and obstetric characteristics among both the groups. The mean age of patients in the couvelaire group was 23.3 and in the non couvelaire group was 22.3.

There was no significant difference in the age, education status, parity and socioeconomic class between the two groups. Overall there were more multiparas as compared to primigravidas in the study population.

Significant difference in vaginal bleeding was observed between two groups (Table 1).
Table 1: Presenting symptoms.

\begin{tabular}{|c|c|c|c|c|c|}
\hline & \multicolumn{4}{|l|}{ Group } & \multirow{3}{*}{$\begin{array}{l}\chi 2, \mathrm{df}, \\
\mathrm{p}\end{array}$} \\
\hline & \multicolumn{2}{|c|}{ Couvelaire } & \multicolumn{2}{|c|}{ Abruption } & \\
\hline & Count & $\%$ & Count & $\%$ & \\
\hline $\begin{array}{l}\text { Vaginal } \\
\text { bleeding }\end{array}$ & 4 & 22.2 & 21 & 75.0 & $\begin{array}{l}12.3,1 \text {, } \\
<0.001 *\end{array}$ \\
\hline $\begin{array}{l}\text { Abdominal } \\
\text { pain }\end{array}$ & 14 & 77.8 & 16 & 57.1 & $\begin{array}{l}2.057 \\
1,0.152\end{array}$ \\
\hline $\begin{array}{l}\text { Uterine } \\
\text { tenderness }\end{array}$ & 11 & 61.1 & 11 & 39.3 & $\begin{array}{l}2.092, \\
1,0.148\end{array}$ \\
\hline Shock & 2 & 11.1 & 0 & 0.0 & $\begin{array}{l}3.253 \\
1,0.071\end{array}$ \\
\hline
\end{tabular}

Table 2: Risk factors.

\begin{tabular}{|c|c|c|c|c|c|}
\hline & \multicolumn{4}{|l|}{ Group } & \multirow{3}{*}{$\chi^{2}, \mathrm{df}, \mathrm{p}$} \\
\hline & \multicolumn{2}{|c|}{ Couvelaire } & \multicolumn{2}{|c|}{ Abruption } & \\
\hline & Count & $\%$ & Count & $\%$ & \\
\hline Chronic hypertension & 3 & 16.7 & 3 & 10.7 & $0.342,1,0.559$ \\
\hline Pre eclampsia & 9 & 50 & 12 & 42.9 & $0.225,1,0.635$ \\
\hline Eclampsia & 4 & 22.2 & 4 & 14.3 & $0.480,1,0.488$ \\
\hline Trauma & 0 & 0.0 & 1 & 3.6 & $0.657,1,0.418$ \\
\hline Multiple gestation & 1 & 5.6 & 0 & 0.0 & $1.59,1,0.207$ \\
\hline Previous LSCS & 4 & 22.2 & 7 & 25.0 & $0.046,1,0.829$ \\
\hline Previous abruption & 3 & 16.7 & 4 & 14.3 & $0.048,1,0.826$ \\
\hline PROM & 2 & 11.1 & 4 & 14.3 & $0.097,1,0.755$ \\
\hline Polyhydraminos & 1 & 5.6 & 2 & 7.1 & $0.045,1,0.831$ \\
\hline
\end{tabular}

Table 3: Maternal complications.

\begin{tabular}{|c|c|c|c|c|c|}
\hline \multirow{3}{*}{ Maternal complications } & \multicolumn{4}{|c|}{ Group } & \multirow{3}{*}{$\chi 2, \mathrm{df}, \mathrm{p}$} \\
\hline & \multicolumn{2}{|c|}{ Couvelaire } & \multicolumn{2}{|c|}{ Abruption } & \\
\hline & Count & $\%$ & Count & $\%$ & \\
\hline PPH & 12 & 66.7 & 8 & 28.6 & $6.47,1,0.011 *$ \\
\hline ICU admission & 7 & 38.9 & 2 & 7.1 & $7.017,1,0.008^{*}$ \\
\hline DIC & 4 & 22.2 & 4 & 14.3 & $0.480,1,0.488$ \\
\hline Prolonged hospital stay & 10 & 55.6 & 8 & 28.6 & $3.349,1,0.067$ \\
\hline Maternal death & 1 & 5.6 & 0 & 0.0 & $1.59,1,0.207$ \\
\hline
\end{tabular}

Table 4: Blood products transfusion.

\begin{tabular}{|c|c|c|c|c|c|}
\hline & \multicolumn{4}{|c|}{ Group } & \multirow{3}{*}{$P$ value } \\
\hline & \multicolumn{2}{|c|}{ Couvelaire } & \multicolumn{2}{|c|}{ Abruption } & \\
\hline & Mean & SD & Mean & SD & \\
\hline $\begin{array}{l}\text { Total } \\
\text { transfusion }\end{array}$ & 5.9 & 3.2 & 1.6 & 1.8 & $<0.001 *$ \\
\hline
\end{tabular}

Group B had significantly higher percentage of vaginal bleeding than Group A. No significant difference was observed between other symptoms between two groups. In the study mean transfusion done in the patients with couvelaire uterus was $5.9 \pm 3.2$ pints and $1.6 \pm 1.8$ pints in the control population (Table 4). This difference in total transfusion done between two groups was significant. All the neonatal complications were more among the patients presenting with couvelaire uterus (Table 5).

\section{DISCUSSION}

To the best of our knowledge this is the first study comparing the feto-maternal outcomes among women with and without couvelaire uterus.

\section{Demographic and Obstetric characteristics of the study participants}

A total of 46 cases of Abruptio placentae who underwent cesarean section were included in the study. Out of these, couvelaire uterus was seen in 18 patients who were allocated as cases and 28 patients without couvelaire uterus were taken as controls for the study. There was no significant difference in the demographic and obstetric characteristics among both the groups. Overall there were more multiparas as compared to primigravidas in the 
study population. This is in line with many previous studies which showed that the occurrence of Abruptio placentae was higher in women with high parity.
Abruption occurs more frequently in older women ( $\geq 35$ years), but usually this increase has been attributed to multiparity ( 3 or more deliveries) independent of age. ${ }^{1}$

Table 5: Neonatal complications.

\begin{tabular}{|c|c|c|c|c|c|}
\hline & \multicolumn{5}{|l|}{ Group } \\
\hline & \multicolumn{2}{|c|}{ Couvelaire (n=18) } & \multicolumn{2}{|c|}{ Abruption (n=28) } & \multirow[t]{2}{*}{$\chi 2, \mathrm{df}, \mathrm{p}$} \\
\hline & Count & $\%$ & Count & $\%$ & \\
\hline Low birth weight $(<2.5 \mathrm{~kg})$ & 15 & 83.3 & 15 & 53.5 & $4.278,1,0.038^{*}$ \\
\hline Still birth/IUD & 6 & 33.3 & 3 & 10.7 & $3.562,1,0.059$ \\
\hline Low Apgar $(<7)$ & 9 & 75.0 & 8 & 32.0 & $6.036,1,0.014 *$ \\
\hline NICU admission & 9 & 75.0 & 13 & 52.0 & $1.779,1,0.182$ \\
\hline Early neonatal death & 5 & 41.7 & 3 & 12.0 & $4.211,1,0.04^{*}$ \\
\hline
\end{tabular}

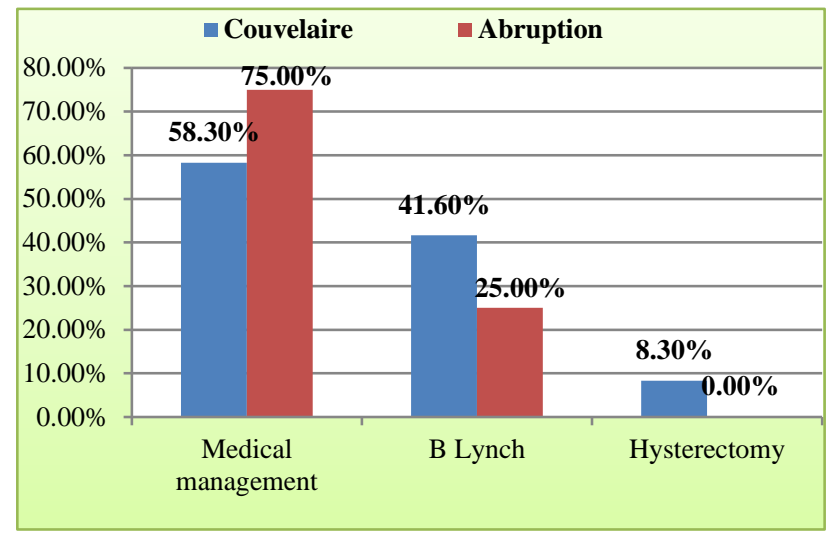

Figure 1: Management of PPH.

$29 \%$ of patients with abruption in present study were over 30 years of age. This is consistent with a study by Mukherjee et al in which $45 \%$ of patients with abruption were over 30 years of age. ${ }^{2}$ Older maternal age may be associated with an increase in obstetric complications secondary to a higher incidence of underlying medical disease, decreased cardiovascular reserve, and diminished ability to adapt to physical stress that may accompany ageing. The increased incidence of diabetes and chronic hypertension and pregnancy induced hypertension with ageing collaterally increases the incidence of abruptio placenta.

\section{Signs and symptoms}

The signs and symptoms of abruption vary depending on the severity of bleeding and degree of separation of placenta. In present study, $75 \%$ of the patients in the non couvelaire group presented with vaginal bleeding while only $22 \%$ with couvelaire uterus had vaginal bleeding. Couvelaire uterus being a complication of concealed abruption explains the disparity in vaginal bleeding. No significant difference in abdominal pain and tenderness was present in both groups. Two patients in the couvelaire group presented with shock. None of the patients in the non couvelaire group presented with shock. The most common presenting complaints in the study population were vaginal bleeding, abdominal pain and tenderness. This is in line with other studies in which the most common presentations included vaginal bleeding, uterine and abdominal pain and tenderness, abnormal uterine contractions, premature labor, maternal hemodynamic stability, fetal distress and fetal death. ${ }^{6}$

\section{Risk factors}

The incidence of risk factors, such as abdominal trauma, multiple gestation, premature rupture of membranes, previous cesarean section, previous history of abruption, polyhydramnios, chronic hypertension, preeclampsia, eclampsia was similar in both groups with no significant increase among the couvelaire group. In present study $60.8 \%$ patients had anemia $(\mathrm{Hb}<10 \mathrm{~g} \%)$ on admission, however it could not be concluded whether anemia was the cause or consequence of antepartum hemorrhage as majority of patients were unbooked with no antenatal records. The most prevalent risk factor for abruption in this study was hypertensive disorders of pregnancy which was present in $88.8 \%$ cases and $67.8 \%$ of controls. These results are consistent with previous studies. ${ }^{7,8,9}$

\section{Maternal outcome}

In comparison with women without couvelaire uterus, women with couvelaire uterus had increased incidence of PPH, DIC and ICU admission as shown in Table 4. Out of these PPH and need for ICU admission was significantly more in the couvelaire group with $\mathrm{p}<0.05$. Furthermore, presence of couvelaire uterus increased the women's need for prolonged hospital stay. There was one maternal death in the couvelaire group and none in the control group. Average blood product transfusion was 5.9 pints in the couvelaire group and only 1.6 pints in the control group. This difference in requirement for blood product transfusion was statistically significant $(\mathrm{p}<0.05)$. 
Among the women without couvelaire uterus who had $\mathrm{PPH}$, only $25 \%$ required $\mathrm{B}$ lynch sutures and none required peripartum hysterectomy.

\section{CONCLUSION}

We conclude that patients with couvelaire uterus had an increased risk of maternal complications such as postpartum hemorrhage and disseminated intravascular coagulation which resulted in increased need for blood transfusion, prolonged hospital stay and maternal morbidity and mortality. Present study further highlights that adverse neonatal outcomes such as low birth weight, low Apgar score and neonatal death were more frequently associated with couvelaire uterus. Thus, the presence of couvelaire uterus may be considered as a severe form of abruption and such patients should be anticipated for higher incidence and risk for maternal and neonatal morbidity.

Funding: No funding sources Conflict of interest: None declared

Ethical approval: The study was approved by the Institutional Ethics Committee

\section{REFERENCES}

1. Kramer MS, Usher RH, Pollak R, Boyd M, Usher S. Etiologic determinants of abruptio placentae. Obstet Gynecol. 1997;89:221-6.

2. Mukherjee S, Bawa A, Sharma S, Nandanwar Y, Gadam M. Retrospective study of risk factors and maternal and fetal outcome in patients with abruptio placentae. J Nat Sc Biol Med. 2014;5:425-8.

3. Hubbard JL, Hosmer SB. Couvelaire uterus. J Am Osteopath Assoc. 1997;97(9):536-7.

4. Alexander JM, Wortman AC. Intrapartum hemorrhage. Obstet Gynecol Clin North Am. 2013;40(1):15-26.

5. Tikkanen M. Placental abruption: epidemiology, risk factors and consequences. Acta Obstet Gynecol Scand. 2011 Feb 1;90(2):140-9.

6. Bodelon C, Bernade- Ortiz A, Schiff MA, Reed SD. Factors associated with peripartum hysterectomy. Obstet Gynecol. 2009; 114:115-23.

7. Toivonen S, Heinonen S, Anttila M, Kosma VM, Saarikoski S. Reproductive risk factors, Doppler findings, and outcome of affected births in placental abruption: A population based analysis. Am J Perinatol. 2002; 19:451-60.

8. Ananth CV, Savitz DA, Williams MA. Placental abruption and its association with hypertension and prolonged rupture of membranes: A methodologic review and meta-analysis. Obstet Gyecol. 1996;88:309-18.

9. Papp Z. Massive obstetric hemorrhage. J Perinat Med. 2003;31(5):408-414.

Cite this article as: Sunanda N, Sruthi T, Sheela SR. Feto-maternal outcome in patients with couvelaire uterus: a 3 year study in a tertiary care hospital in rural Karnataka, India. Int J Reprod Contracept Obstet Gynecol 2018;7:503-7. 